\title{
Technology leadership in Saudi schools
}

\author{
Abdullah Alenezi ${ }^{1}$ \\ Published online: 17 March 2016 \\ C The Author(s) 2016. This article is published with open access at Springerlink.com
}

\begin{abstract}
This paper demonstrates the potential of Saudi schools for technology leadership provided by Learning Resource Centres (LRCs) to enhance the formation of a technology-motivated educational environment. Using the grounded theory methodology and the CBAM stages of concern and levels of use this study sheds light on Saudi LRCs and their leadership role within the framework of the ongoing ICT-related education reform. From the interviews of the participants in the training programme at Northern Borders University, Saudi Arabia, it is found that Saudi schools require standardized technology leadership to implement standardized uses of technology via networked LRCs. The Saudi teachers with little knowledge of technology can use LRCs.
\end{abstract}

Keywords Learning resource centre (LRC) · Technology leadership · ICT implementation · Mandate to technology leadership · Integration strategies

\section{Introduction}

ICT-related education reform was launched in Saudi Arabia at the turn of the millennium. In compliance with this reform, Saudi teachers have automatically turned to mandatory ICT adopters (Al-Madani and Allaafiajiy 2007, p. 30). With this reform, there emerged ICT-related Learning Resource Centres (LRCs) in Saudi schools. Since the start of the reform, the Saudi Ministry of Education provided Saudi teachers and LRC administrators (specialists) with training programs. These programs train teachers how to use ICT tools, inform them about the advances in technology, and supply them with theoretical and technical knowledge that they can apply in their immediate school settings. However, Saudi teachers are under pressure regarding ICT implementation because it is in conflict with traditional offline methods of education and challenges

Abdullah Alenezi

abdullah.a.alenezi@nbu.edu.sa

1 Northern Borders University, Arar, Saudi Arabia 
conventional educational environments. The recent decade of Saudi education reform has shown that ICT adoption is only the first stage within a holistic approach to ICT integration (Shaabi 2010). The long-expected shift from ICT adoption to ICT implementation has been slow. Saudi schools have had problems with making ICT tools available in working condition, and Saudi teachers lack their own initiatives to effectively implement ICT. It is apparent that the instrumental mandate given to an individual teacher is not enough to make ICT-related change with a view of creating a drastically new educational environment. The Saudi mandate nullifies the difference between early and late adopters of technology and challenges individual initiatives related to technology leadership. "Adopting quality systems standards in education" (Brief Report 2010, p. 57) is at the heart of a long-term change of perspective.

The present study raises the following research questions:

- What impedes school LRCs from nurturing technology leaders?

- What kind of technology leader functions as an ICT implementer?

- What integration strategies can strengthen technology leadership in Saudi school settings?

\subsection{The concept of technology leadership in Saudi Arabia}

The educational technology field focuses on educational technology leadership from the perspective of leadership models and technology leadership experiences (Miller and Curry 2014). Technology leadership in technology-oriented schools involves not only administration but also other members of school staff. Today, teacher leadership has become a commonplace topic globally; it is studied in relation to learning and teaching, leadership and vision, assessment and evaluation, professional practice and productivity, and sociolegal and ethical issues (Hughes et al. 2005). The problem of standardized technology leadership in schools is on the agenda (Hamzah et al. 2014). School administration's technology leadership is given priority in the process of teachers' technology implementation (Raman et al. 2014). However, there is a strong demand to distributing the roles of technology leadership within schools (Duze 2012). In local contexts, technology leadership can be delegated to technology leaders who are responsible for LRCs. Yet, this specific group of technology leaders is ignored in current research. The specific role played by these leaders in the Saudi context raises the problem of using LRC's leaders as a driving force to lead ICT integration in Saudi schools.

The Saudi Ministry of Education supervises more than 25,000 primary, middle, and secondary schools in 42 educational districts across Saudi Arabia. Most schools are state run. ICT as a subject was introduced in Saudi schools in 1985. The ICT-related reform was launched in Saudi schools in 2004. Gradually school libraries were transformed into LRCs. In 2008, there were 1500 LRCS in Saudi schools. Computer-based laboratories and digital technical centres were established to support school curricula (Oyaid 2009, p. 19, 23). This Saudi ICT-related educational reform still fails to meet many expectations. Although Saudi teachers are required to use technology, they are poorly trained and have no clear vision of technology-based alternatives to traditional methods of teaching. The present demand for standardized ICT-related practices can be promoted by Saudi LRCs. Alkrdem (2014) identifies such areas of standardization in Saudi secondary schools as 
technology leadership and vision, teaching and learning process, productivity and professional development, support, management, evaluation, and social/legal/ethical issues. From his findings, it is Saudi headmasters who should assume technology leadership. Almalki and Williams (2012) claim that technology leadership cannot be separated from a suitable ICT infrastructure environment and training, which is strategic to Saudi ICT-related reform across all stages of education.

The King Abdullah Project for General Education and Development known as Tatweer project was launched in 2007; 25 Saudi schools for boys and 25 schools for girls were selected to participate in it. In 2015 the number of Tatweer schools amounted to 60 (Alghamdi and Higgins 2015, p. 3). The government-owned Tatweer Holding Company in Saudi Arabia was founded to support the development of the public educational system in compliance with this nationwide project. This company helps the Saudi Ministry of Education implement teacher quality initiatives in such subject domains as English, science, technology, engineering, and mathematics. Tatweer schools test reforms and monitor their implementation within a Tatweer pilot programme. Such schools have technical resources but it remains disputable how to harmonize the religious ideology that underpins the system of education in Saudi Arabia with the slow pace of ICT integration. According to Alyami (2014), the Tatweer programme promotes the idea of excellence teams whose members function as school leaders, leading teachers, special-needs learning coordinators, activity specialists, and others. This idea, from this researcher's findings, finds staff resistance which is up to $70 \%$. Alyami claims that the teachers prefer to leave schools rather than change their practices. Henceforth even such pilot programmes have difficulty turning schools into autonomous, self-managed organizations with more rights delegated to them from the decentralized educational system. ICT adoption, or the presence of technology in a school setting, is not enough to integrate ICT into highly traditional Saudi schools because no effective infrastructure is built. This problem can be solved by delegating technology leadership to LRCs. Such centres can trigger an ICT-related shift within the inherited centralized system that fails to praise technology leadership and technology leaders. As many Saudi schools have LRCs, these technologicallyadvanced units can be used as drivers of technology leadership in the Saudi school context. Indeed, time and effort are needed to develop a new culture of learning and teaching in a technology-based environment that will nurture technology leaders with highly motivated self-development needs. With availability of LRCs across the country and their accountability for ICT integration in their schools, these centres can standardize their ICT-related practices to enforce technology leadership that goes beyond formal ICT adoption freed from technology leadership involvement.

\subsection{Theoretical background and research design}

The present study uses the adoption model that indicates further activities related to ICT integration in the educational process (Passey 2010, p. 70). As Saudi teachers have a mandate to adopt ICT, this model highlights the stages of concern and levels of use (Hall 2010) concerning a phased approach to ICT adoption within the holistic process of ultimate ICT integration. ICT adoption is a way to ICT integration through ICT implementation. When schools move to higher stages of concern and levels of use they make consistent efforts to implement technology in a motivated way. This research benefits from 
the theory of planned behaviour, which focuses on factors affecting a person's intention to change including a personal desire for change, social pressure of change, and the ease/difficulty of performing the behaviour of change (Pierce and Ball 2009, p. 300).

In the Saudi context, planned behaviour is prescribed by an ICT-related education reform that mandates Saudi teachers to be ICT adopters. In the current study, evaluation is a method of reviewing ICT adoption, or a requirement to use technology in teacher practices, within the phased ICT integration, which is a shift from required, mandatory ICT adoption to ICT implementation whose product and ultimate goal is ICT integration. Evaluative evidence is collected with regard to technology leadership, or ICTrelated operations, provided by school LRCs. Planned behaviour is important to the Saudi context because there is difficulty moving on from ICT adoption (the availability of ICT adopters who have ICT tools at their disposal) to further ICT implementation (pedagogical uses of technology which are contextualized and standardized to enhance an ultimate goal of ICT integration). In other countries that are reforming their education system, technology leadership is considered, like in Malaysia, together with standards of quality education (Hamzah et al. 2014). The Malaysian studies also demonstrate that technology leadership can be top-bottom oriented (technology leadership of school headmasters) (Raman et al. 2014). However, in the Saudi context school administration fails to assume a technology leadership role. In this situation, this role can be assumed by existing LRCs.

The grounded theory approach (Scott and Howell 2008; Glaser and Strausss 2012) is a way to construct evidence pertinent to this study's research questions. Glaser \& Strauss claim that "theory based on data can usually not be completely refuted by more data or neglected by another theory" (Glaser and Strausss 2012, p. 4). Grounded theory research generates theory from collected data with a clear purpose of determining the existing ways of ICT integration and their corrections when they fail to implement ICT integration consequently. The analysis of emerging categories involved in technology leadership is crucial to the formation of theory of ICT integration in modern schools of learning. As grounded theory involves a bounded context in which the researcher looks for "seed concepts" (Urquhart 2013, p. 13), this methodology can be effectively used to build a theoretical background of technology leadership in Saudi schools.

Focused coding synthesizes the data collected within a simultaneous process of data collection and data analysis. It attempts to generalize emerging categories to build an integration theory of educational change. The researcher investigates a difference between being an LRC's technology leader and technology leadership of LRCs (networked and standardized ICT-related teacher practices). A single-theme design was selected to compare individual uses of LRCs (the formation of a technology leader on the basis of LRCs) with potential collaborative uses of such centres by the teachers who start functioning as technology leaders in their school settings.

The researcher conducted a structured interview with 16 male school LRC administrators to determine their stages of concern and levels of use. The grounded theory approach with a thematic analysis of technology leadership is utilized to categorize planned behaviour within a change paradigm and to develop integration strategies with regard to successive steps - this promotes technology leadership through the coordinating and collaborative efforts of LRCs. This orientation is backed by the personal perceptions of the interviewees with regard to their technology leadership in their immediate school environments. 


\subsection{Data collection}

Data was collected from the Saudi school administrators (specialists, assistants) who participated in a training program at Northern Borders University (NBU). Using an interview with 30 pre-written questions, the researcher selected 16 participants who are in charge of their school's LRC. All selected participants were experienced teachers (from 8 to 30 years) and ICT adopters. They represented four Saudi provinces: Northern Borders, Aljouf, Tabuk, and Almadinah Almunawarah. They attended ICTrelated training courses at least once. All of them were males because male and female teachers attend training programmes separately in the Saudi segregated educational context.

\subsection{Data analysis}

Levels of use The participants were asked to self-assess their technology competence as "good", "satisfactory", and "not satisfactory". One participant rated his ICT skills as "satisfactory" and six participants answered that their ICT skills were "good". Eight participants rated their ICT skills as "very good" and one participant stated that his ICT skills were excellent (he connected his excellence with regular uses of videos at his lessons). The participants' favourite ICT tools are computer (15 participants), data show displays (7 participants), interactive smart board (7 participants), document camera (2 participants), and Internet (1 participant). All participants responded that they received training in ICT use. In their responses to the question "What is ICT adoption to you?" the participant with self-assessed "excellent" uses of ICT said, "It is that I am a person with a positive attitude to the role of teaching with technology". The participants with self-assessed "very good" uses of ICT reported a drastic change ("leap") in the educational process, self-development, teaching and learning with modern methods. They also help others use technology, are positive to the presence of technology, and address technology as the future of education. The participants with self-assessed "good" uses of ICT pointed to self-development, adaptability to ICT-related change, teaching with technology and the use of LRCs to enhance knowledge and information about technology. The participant with self-assessed "satisfactory" skills said that ICT adoption for him is "full knowledge, interest, and dexterity".

Based on Hall's levels of use (2010) and the answers to the questions related to the participants' ICT skills and regularity of using technology, the researcher rated the participants' levels of use as Level IVB-Refinement (1 participant whose self-assessed level of use is "excellent"), Level IVA-Routine (4 participants), and Level IIIMechanical (11 participants). This shows that the participants are ICT adopters who mainly never go beyond mechanical levels of use. Most of them accept the routine (formal) presence of technology but only one of them demonstrates motivation to refine levels of use and move from mechanical (routine) levels of use to higher ones. Technology leadership begins with the IV levels of use because this makes the routine presence of technology meaningful to ICT-related change. The participants who demonstrate the fourth level of use have stopped before the integration level of use whose characteristic feature is that the teacher is making deliberate efforts to coordinate with other teachers in ICT uses. 
Stages of concern The participants' stages of concern were analysed with regard to their perception of technology leadership from a personal and LRC management perspective. The participants were asked what technology leadership was personally for them. From their answers the following topics were identified: (1) technology leadership is a way towards ICT integration (the optimal uses of technology and ICTbased methods of teaching); (2) technology leadership is a synonym for technology management (using appropriate ICT tools, knowledgeable uses of available ICT tools); (3) technology leadership is a prerequisite for ICT implementation (active and efficient uses of ICT required by the academic content); (4) technology leadership is controlled uses of ICT tools ("full control and getting the best we can from them"); (5) it is intercommunication; (6) it is inclusiveness in the digital age (the global demand of the current age); (7) technology leadership is a path towards success and excellence in teacher performance; (8) it is the ability to use technology on a regular basis; (9) it is learner-centred teacher performance; and (10) it is "futuristic education".

The participants formulated those qualities that, in their view, a Saudi technology leader should have. To them, technology leaders should be knowledgeable in ICT uses, motivated, trained, have a command of English, be informed about the latest advances in technology, be capable of keeping the available ICT tools safe, be experienced, and benefit from pedagogical uses of technology. In their responses to the question "If you were a technology leader, what would you like to change?" one participant found no answer; four participants would keep the LRCs safe and clean; one participant linked technology leadership with proper uses of ICT.

In their responses to the question "What do you lack as a potential effective technology leader", almost all participants mentioned their lack of training; one participant gave no answer; one participant connected his lack of training with managing an LRC in a scientific way. The participants had concerns about insufficient financial support of Saudi LRCs as well as a lack of moral and material support, the necessity of special financial funding of LRCs, and recognition of the importance of LRCs in the Saudi school context. They responded that an effective LRC should be well equipped with technology as well as technical support. There should be physical, human and technological resources combined to maintain LRCS as a technology-learning environment.

From the data collected, 2 participants are at the personal stage of concern, 5 are at the management stage of concern, and 9 are at the consequence stage of concern. At the management state, the user starts being concerned about the task in hand, whereas at the consequence stage of concern (s) he is concerned about the results exhibited after the implementation process in the form of students' accomplishments. The perceived trend is a movement to higher stages of concern - from the personal stage of concern to the management stage of concern and to the consequence stage of concern. Corresponding to the CBAM model, two higher stages of concern - the collaborative stage of concern and the refocusing stage of concern - are not employed in the Saudi context. The stages of concern remain individual, dealing with personal ICT-related practices. In a similar way, the participants showed no integration levels of use. Something impedes them from moving to the higher collaborative stage of concern and integration level of use. It shows that in technology leadership there can be defined at least two phases: ICT adoption that shapes a technology leader and ICT implementation that builds technology leadership of technology leaders who function as ICT implementers. 
Perceptions of technology leadership The participants gave their views of what it means for them to be an effective technology leader. They responded that a technology leader should be in charge of an LRC, so they viewed their personal technology leadership from the LRC management perspective. Such a technology leader should be well informed about technology and integrate technology into a school educational environment and have a great responsibility for being in charge of an LRC. He should be an ICT specialist and should function as a technical advisor. He should instruct teachers how to use available technology and be skilful in using technology. In their responses to the question "Have you ever shown your leadership skills?" all but one interviewee answered this question in the affirmative. One participant responded that he personally organized an LRC in his school and one participant said that he introduced technology to his school. Four participants failed to answer the question whether it is rewarding to be a technology leader or not - the others gave a positive answer. They, however, did have concerns about favouritism and obstacles to the use of ICT. One participant thinks that it is a great responsibility rather than rewarding to be a technology leader. All participants share the view that a person responsible for an LRC should be well trained. Some of them expressed the view that an LRC administrator should conduct courses to familiarize teachers with pedagogical uses of technology and the latest advances in technology. One participant thinks that motivating teachers is a responsibility of an LRC administrator, which can be achieved by writing brochures and research activities.

The participants were asked how they would change in case they assumed a role of their school's technology leader. The responses were as follows: personal improvement in using technology; keeping technology safe; be more knowledgeable about technology; keeping pace with technological advances; and focusing on innovation. All in all, they mentioned positive change. The participants expressed their vision of the future of LRCs: (1) LRCs will soon become obsolete after the emergence of interactive classes; (2) There is a need for portable LRC with a movable table and a computer connected to the Internet - the data display should be available in every classroom; (3) LRCs will turn into digital libraries with technical support; (4) They will be operated by a technical supervisor or maintenance technician; (5) There will be no favouritism in selecting LRC administrators;(6) The progress will be moderate; and (7) There needs to be a new department at Saudi universities with regular training and standardized equipment. On the whole, the participants fail to view personal technology leadership as inherent in collaborative technology leadership. Their visions of personal technology leadership and LRC management are blurred and show the absence of a standard that would help move to higher levels of use and stages of concern.

\subsection{Emerging categories related to technology leadership of LRCs}

1. The interviewed participants were asked what ICTs should be obligatory in Saudi LRCs. Their lists contained a computer, projector, interactive smart board/computer, Internet connection, interactive smart board/computer; data show display, and interactive smart board. Half of the participants specified an interactive smart board as a standard ICT tool in LRCs. Only one participant mentioned high speed DSL. The participants include light movable chairs and scientific books to the list of equipment in the LRCS. From this, the first emerging category can be singled out: 
technology leadership of LRCs in the Saudi context can be achieved when they are equipped with standardized ICT tools, digital resources, and other materials. In this regard, 12 participants responded in the affirmative that the Ministry of Education should prescribe the work of LRCs; two participants said that the Ministry of Education had already set standards, and two participants think that the function of the LRCs should not be prescribed by the Ministry of Education.

2. The participants were asked "Is your school administration free to implement its vision of a LRC?" Six participants responded to this question in the negative. One participant said that this vision was implemented in a certain extent. Other participants expressed the view that their school administration was free to develop its own vision of how an LRC should function in their specific learning environment. In their responses to the question "Do you know any LRCs that can serve as a model?",six participants answered in the negative, one participant considered his school's LRC being a model, and others said that (1) the LRCs were the same or that model LRCs do exist (e.g. Allah bin Abbas primary school and Shiabah bin Othman primary school). The emerging category is: Technology leadership of LRCs is not connected with a school's specific vision of an LRC.

3. The participants claim that it is the task of LRCs to conduct training courses and inform teachers about innovation and turn LRC administrators into technical supervisors/maintenance technicians and developing movable LRCs that can be used in every school setting. The emerging category is: Technology leadership of LRCS is in conducting courses for teachers and making them knowledgeable about innovation.

\section{Discussion}

Passey (2010) assumes that the process of ICT integration is implemented via three phases - the "self" phase, the "task" phase", and the "impact" phase. The completeness of one phase leads to another phase that is influenced by the factors that are specific to it. The emerging categories can be formulated as a core category: In the Saudi context, technology leadership of LRCs should be based on standardized tools within the framework of a technology-based infrastructure supervised by academic universities. The key issues of promoting the issue of technology leadership through LRCs are: (1) supervision of innovation in a school setting; (2) conducting courses to involve teachers in teaching with technology by using the LRC resources; (3) creating an innovative educational environment around LRCs; (4) technical supervision of technology through LRCs; (5) arrangement of workshops on the basis of LRCs; and (6) regular training of all LRC instructors. In accordance with Passey's three stages, the Saudi coordinators of LRCs know their task to arrange the uses of technology in a school setting. However, there are no traces of the "impact" phase. The LRCs are available and open to the uses of technology but this is formalized as a requirement for ICT adoption with no standards of ICT-related quality education being formulated.

In the Saudi school context, mandatory ICT adoption automatically turns Saudi teachers into ICT adopters. In this phase it is important to address ICT uses at the mechanical level because Saudi schools are poorly equipped with technology. Passey and Hobrecht (2001) claim that effective uses of ICT are those that have high 
educational value, reconstruct teacher performance, help fulfil clear-cut purposes, are planned, and possess high potential and quality. Planned uses of LRCs in the Saudi context reconstruct teacher performance. However, this can be under pressure of prescribed ICT adoption provided by the on-going education reform. Although the interviewed participants felt high potential of ICT-related quality education, they had difficulty identifying the high potential value of collaborative uses of LRCs. From their perceptions, technology leadership is an individual rather than collective responsibility.

From the data collected, it can be assumed that technology leadership is poorly shaped as a driver of ICT implementation in Saudi schools via effective uses of LRCs. The LRC administrators are mainly teachers who are entrusted with the task of supervising an LRC. They are individuals who are not used to collaborative levels of use and integration stages of concern. Most of them, based on the present research, are at the mechanical level of use and at the consequence stage of concern. Most participants failed to view technology leadership in terms of collaboration - their attitudes to technology are limited to self-development and formation of personal positive attitudes to teaching with technology. Only one participant connected ICT use to the role of LRCs in ICT adoption and further ICT integration through ICT implementation. Only one participant thought of ICT adoption and technology in terms of using LRCs to help other teachers teach with technology.

\subsection{Integration strategies related to technology leadership of LRCs}

For this, integrated strategies related to technology leadership of LRCs need to be developed. First, LRCs in the Saudi context, namely, in a collective culture, can turn into collaborative technology centres where teachers can exchange experience and innovative ideas, as well as attract more students who are embedded in a technologyfriendly environment. This will contribute to ICT integration whose product is technology leadership formation. Second, LRCs can be improved by standardized tools that are recommended by the Ministry of Education. With standardized ICT tools at their disposal, schools will be able to focus on technology leadership that addresses operational issues and pedagogical uses of these tools. Third, through the process of using LRCs and exchanging collegiate ICT-related opinions, entire schools will be able to create their specific vision of what LRCs need when they are supplied with a guaranteed list of standardized ICT tools. This will contribute to LRC networking across school settings, which will enhance ICT integration processes. Finally, with less pressure on technology innovation, LRCs will become centres of innovative teaching and learning - innovative motivators can change both teachers and students. In the Saudi context, LRCs can attract both teachers and students that cooperate and develop technology leadership skills following the demands of the present-day digital age. LRCs should be available to all students and teachers who will benefit from their technology leadership.

From this study's data analysis, the following integrated strategies to strengthen the role of LRCs in Saudi schools are recommended:

- Regular training of innovators through innovation. There is currently a lack of training, which is the main obstacle to higher stages of concern and levels of use among potential technology leaders in Saudi school settings. 
- Emphasizing the task of teaching with technology including attracting the largest portion of teachers and students, creating a blended learning environment, and connecting self-development with technology excellence. Currently, scheduled uses of LRCs substitute motivated uses of LRCs. Teachers hold classes in LRCs mainly because of the pressure of their mandate to technology.

- Standardized equipment of LRCs to optimize their role in a school setting. Old and haphazard equipment impedes trust and confidence in technology leadership of Saudi school LRCs.

- Selecting via open competitions would allow LRC administrators who are innovators and motivators as well as ICT specialists and experienced in technology. Saudi teachers are aware of favouritism and are reluctant to connect with a real competition of technology leaders.

\section{Conclusions}

LRCs are inherent in Saudi educational environments, but their role in specific school settings is not connected with technology leadership, which nurtures school's innovation and innovators. With a national guideline to ICT adoption, Saudi teachers are aware and informed about the necessity of teaching with technology. However, they have difficulty moving to higher stages of concern and levels of use because they fail to use LRCS as a new educational environment that can perform technology courses, exchange ideas, and reduce resistance to innovation. The Saudi LRCs can play a role of technology leader that promotes self-development with teaching excellence. In the Saudi context, this assumed technology leadership will be in harmony with collective culture and quality education.

The absence of a standardized concept of LRC as responsible for technology leadership in specific school environments impedes the process of nurturing technology leader in Saudi schools. A Saudi school technology leader can function as an ICT implementer who is knowledgeable, informed, motivated, and skilled at leading ICTrelated change with other teachers via their school's LRC. Technology leadership in Saudi schools can be strengthened by the following integration strategies: (1) acquisition of Saudi standards of quality LRCs; (2) availability of standardized ICT tools and regular training to attract more teachers to work in LRCs; (3) exchange of experience and ideas among LRCs under the supervision of universities that provide training courses for LRC administrators and specialists; (4) administrative support of technology leaders in a school setting; and (5) establishment of a blended learning environment on the basis of standardized LRCS. Saudi schools can facilitate to create a technology leader who is responsible for an LRC and unites efforts of school staff within the ongoing process of ICT integration. A technology leader in the Saudi context is an ICT implementer whose practices are oriented to highest stages of concern and levels of use.

These results may be biased because the researcher focused on LRCs in Saudi schools for boys. Recognizing this limit, the researcher will train a female assistant to interview female LRC assistants. Also, the participants represented only four of the Saudi provinces. This study is a pilot study because it tests grounded theory research methods for exploring technology leadership in Saudi schools. 
Open Access This article is distributed under the terms of the Creative Commons Attribution 4.0 International License (http://creativecommons.org/licenses/by/4.0/), which permits unrestricted use, distribution, and reproduction in any medium, provided you give appropriate credit to the original author(s) and the source, provide a link to the Creative Commons license, and indicate if changes were made.

\section{References}

Alghamdi, A. \& Higgins, S. (2015). Investigating how teachers in primary schools in Saudi Arabia were trained to use interactive whiteboards and what their training needs were. International Journal of Technical Research and Applications, Special Issue 30, 1-10. Retrieved from http://www.ijtra.com/ special-issue-view/investigating-how-teachers-in-primary-schools-in-saudi-arabia-were-trained-to-useinteractive-whiteboards-and-what-their-training-needs-were.pdf

Alkrdem, M. (2014). Technological leadership behaviour of high school head teachers in Asir Region, Saudi Arabia. Journal of International Educational Research, 10(2), 95-100.

Al-Madani, F.M. \& Allaafiajiy, I.A. (2007). Teachers' professional development on ICT use: A Saudi sustainable development model. GSE E-Journal of Education, 28-35. Retrieved from http:// worldconferences.net/journals/gse/papergse/G 043 - FERAS MOHAMMED AL-MADANI_ TEACHERS PROFESIONAL DEVELOPMENT_read.pdf

Almalki, G., \& Williams, N. (2012). A strategy to improve the usage of ICT in the Kingdom of Saudi Arabia primary school. International Journal of Advanced Computer Science and Applications, 3(10), 42-40.

Alyami, R. H. (2014). Educational reform in the Kingdom of Saudi Arabia: Tatweer schools as a unit of development. Literacy Information and Computer Education Journal, 5(2), 1424-1433.

Brief Report on the Ninth Development Plan: 2010-2014 (2010). Kingdom of Saudi Arabia, Ministry of economy and planning. Retrieved from https://chronicle.fanack.com/wp-content/uploads/sites/5/2014/ archive/user_upload/Documenten/Links/Saudi_Arabia/Report_Ninth_Development_Plan.pdf

Duze, C.O. (2012). The changing role of school leadership and teacher capacity building in teaching and learning. Journal of Emerging Trends in Educational Research and Policy Studies, 3(1), 111+. Retrieved from https://www.questia.com/read/1P3-3086871821/the-changing-role-of-school-leadership-and-teacher

Glaser, B.G. \& Strausss, A.L. (2012). The Discovery of Grounded Theory: Strategies for Qualitative Research. New Brunswick (U.S.A.) \& London (U.K.): Aldine Transaction

Hall, G. E. (2010). Technology's Achilles heel: Achieving high-quality implementation. JRTE, 42(3), 231253.

Hamzah, M.I.M., Juraime, F., Hamid, A.H.A., et al (2014). Technology leadership and its relationship with School-Malaysian Standard of Education Quality (School-MSEQ). International Education Studies, 7(13), 278+. Retrieved from https:/www.questia.com/read/1P3-3577466831/technology-leadership-andits-relationship-with-school-malaysia

Hughes, J.E., McLeod, S., Dikkers, A.G., et al (2005). School technology leadership. Academic Exchange Quarterly, 9(2), 51+. Retrieved from https:/www.questia.com/read/1G1-136071077/school-technologyleadership-theory-to-practice

Miller, C.T. \& Curry, J.H. (2014). But I don't want to be a professor! The innovations of an online practitioner doctorate focused on educational technology. Quarterly Review of Distance Education, 15(13), 35+. Retrieved from https://www.questia.com/read/1P3-3614342161/but-i-don-t-want-to-be-a-professor-theinnovations

Oyaid, A. A. (2009). Education policy in Saudi Arabia and its relation to secondary school teachers' ICT use, perceptions, and views of the future of ICT in education. $\mathrm{PhD}$ : University of Exeter.

Passey, D. (2010). Technology enhancing learning: Analyzing uses of information and communication technologies by primary and secondary school pupils within learning frameworks. The Curriculum Journal, 17(2), 139-166.

Passey, D., \& Hobrecht, P. (2001). Online resources and effective teaching and learning. Education 3-13, 29(1), 3-8.

Pierce, R., \& Ball, L. (2009). Perceptions that may affect teachers' intention to use technology in secondary mathematics classes. Studies in Mathematics, 71, 299-317. doi:10.1007/s10649-008-9177-6.

Raman, A., Don, J., \& Kasim, A.L. (2014). The relationship between principals' technology leadership and teachers' technology use in Malaysian secondary schools. Asian School Science, 10(18), 30+. Retrieved 
from https://www.questia.com/read/1P3-3421714971/the-relationship-between-principals-technologyleadership

Scott, K.W. \& Howell D. (2008). Clarifying analysis and interpretation in grounded theory: Using a conditional relationship guide and reflective coding matrix. International Journal of Qualitative Methods, 7(2). Retrieved from http://creativecommons.org/licenses/by/20

Shaabi, I. (2010). ESP Community in Transition: A study of ICT use in a tertiary context in Saudi Arabia. Doctor of Education Thesis, Faculty of Education. University of Wollongong. Retrieved from http://ro. uow.edu/au/theses/3136

Urquhart, C. (2013). Grounded Theory for Qualitative Research: A Practical Guide. London: SAGE. 